\title{
Immunohistochemistry of Brain Arginine Vasotocin and Isotocin in False Clown Anemonefish Amphiprion ocellaris
}

\author{
Eri Iwata $^{1}{ }^{*}$, Yukiko Nagai $^{2}$ and Hideaki Sasaki ${ }^{1}$ \\ ${ }^{1}$ College of Science and Engineering, Iwaki Meisei University, Iwaki, Japan \\ ${ }^{2}$ Bio Medical Laboratories, INC., Saitama, Japan
}

\begin{abstract}
The brain nanopeptides arginine vasotocin and isotocin are considered to be involved in the regulation of social and reproductive behavior in teleosts. We investigated the immunoreactivity of brain arginine vasotocin and isotocin neurons in four pairs of the protandrous false clown anemonefish Amphiprion ocellaris (Cuvier, 1830). After 450 days of pairing, the social rank of each individual was clearly distinguishable by body mass. The resident-intruder model test revealed that dominant individuals tended to display agonistic behavior more frequently than subordinate individuals, yet pairing failed to induce sex differentiation by social rank (i.e., gonadosomatic index and steroid profiles did not differ significantly and the gonads were ovotestes in both social rank individuals). However, dominant individuals had a larger size of arginine vasotocin neurons in the magnocellular layer and a greater number of isotocin neurons in the parvocellular layer of the brain preoptic area (POA) than did subordinate individuals. Arginine vasotocin and isotocin neurons of each layer of the POA showed different projection patterns: in the magnocellular layer, the fibers innervated the medial zone of the telencephalon and the mesencephalic tegmentum, but not in other layers. These results suggest that vasotocin and isotocin neurons in the brain of $A$. ocellaris regulate social behavior and have different roles.
\end{abstract}

Keywords: Anemonefish, Brain nanopeptides, Sex differentiation, Aggression.

\section{INTRODUCTION}

Among sex-changing fishes, anemonefishes (genus Amphiprion) are unique, socially controlled, protandrous sex changers with a monogamous mating system. They live symbiotically with sea anemones in the tropical waters of the Indo-Pacific, forming a social unit consisting of a monogamous pair and several nonbreeders or juveniles. Females are the largest and dominant members of social groups, displaying frequent aggressive behavior toward other group members. The second-ranked individuals become males, and others remain as nonreproductive individuals. If a female disappears from the social unit, a male changes sex and the largest of the nonbreeders becomes a functional male $[1,2]$. At the same time, under certain conditions immature anemonefishes with ambisexual gonads differentiate directly into males or females. Nonbreeding Amphiprion clarkii (Bennett, 1830) in temperate waters can become females without passing through a functional male stage, because suppression by the dominant fish is avoided by the high density of available sea anemones and the small population size of A. clarkii [3]. When juvenile anemonefish are raised together in captivity, the largest will become a female and the next largest a male, whereas the rest will remain sexually immature [4].

Meanwhile, brain nanopeptides, arginine vasotocin (AVT) and isotocin (IT) are thought to be involved in social

\footnotetext{
*Address correspondence to this author at the College of Science and Engineering, Iwaki Meisei University, Iwaki, Japan; Tel: +81-246-29-7157; Fax: +81-246-29-0577; E-mail: asealion@iwakimu.ac.jp
}

and reproductive behavior in teleosts. Our previous study revealed that 90 days after group formation false clown anemonefish Amphiprion ocellaris (Cuvier, 1830) had different brain AVT phenotypes according to their social rank [5]. The relationship between AVT and IT, however, is still unclear, as is the involvement of these peptides in the social behavior of anemonefish. We therefore evaluated the number and/or size of AVT- or IT-immunoreactive (-ir) neurons in the preoptic area (POA) of the brain of A. ocellaris kept in pairs for 450 days. Territorial behavior, concentration of plasma steroids, and histological appearance of gonads were also assessed.

\section{MATERIALS AND METHODOLOGY}

\section{Animals}

Captive-bred sexually immature A. ocellaris 12 months after hatching (provided by Dr. T. Furuta, Environmental Science Research Laboratory, Central Research Institute of Electric Power Industry, Chiba, Japan) were kept in a 56-L tank with a closed circulatory system at 25 to $26{ }^{\circ} \mathrm{C}$ under natural light. The fish were held in a group of 30 to 50 individuals to suppress sexual maturation until the experiment started. Fish were fed commercial pellets (Omega One Marine Flakes, Omega Sea, Ltd, OH) daily throughout the experiment.

Two individuals were moved to each of four $26-\mathrm{L}$ experimental tanks and kept for 450 days for social rank formation and behavioral observations $(n=4$ pairs). A PVC waterpipe joint (50 $\mathrm{mm}$ diameter) substituted for a host sea anem- 
one [6] and was placed at the center of the experimental tank as a shelter. Each individual in a tank was identified by differences in the white-striped pattern on its body and classified as $\alpha$ (dominant) or $\beta$ (second-ranked) from behavioral observations on Day 0 of the experiment [6].

Experimental protocols followed the Japan Ethological Society Guidelines for Research on Animal Behavior (2003) and the U.S. National Institutes of Health (NIH) Guide for the Care and Use of Laboratory Animals (1985).

\section{Behavioral Analysis}

To evaluate the development of territorial aggressiveness, resident-intruder model tests were conducted on Days 7, 91, 175,259 , and 427 of the experiment. A water-filled clear plastic pillar-shaped compartment was placed at one end of the experimental tank 4 days before the introduction of an intruder, and the compartment was removed and replaced every day at 8:30 in the morning for habituation to the experimental procedure. On the fifth day, an intruder, which was sexually immature and smaller than the $\beta$ individual, was placed in the plastic compartment and introduced to the experimental tank at 8:30 in the morning. The behaviors of the $\alpha$ and $\beta$ fish were then videotaped for $5 \mathrm{~min}$. The following four behaviors of each experimental fish were observed: duration of approaching an intruder, latency period before touching the compartment, frequency of lunging, and frequency of displacement aggression to a tank mate. The descriptions of the behavioral parameters are provided in Table 1

Table 1. Behavioral Parameters of A. ocellaris

\begin{tabular}{|c|c|}
\hline Behavior & Description \\
\hline \hline Approach & $\begin{array}{r}\text { Duration of focal individual was in be- } \\
\text { tween shelter and case. }\end{array}$ \\
\hline Latency & $\begin{array}{c}\text { Latency of focal individual to touch the } \\
\text { case by its mouth. }\end{array}$ \\
\hline Touch & Frequency of focal individual to touch the \\
\hline Lunging & $\begin{array}{c}\text { Frequency of rapid, directed swimming } \\
\text { movement to approach an intruder. }\end{array}$ \\
\hline Displacement & $\begin{array}{r}\text { Frequency of focal individual lunges to- } \\
\text { wards its tank mate. }\end{array}$ \\
\hline
\end{tabular}

\section{Sample Collection and Measurement}

On Day 450 of the experiment, fish were anesthetized with MS222 (tricaine methanesulfonate; Sigma-Aldrich, St. Louis, MO), and total body length and weight were measured. Blood samples were collected from the caudal vessel of each fish using a heparinized capillary tube and centrifuged immediately. The plasma was removed and stored at $-20^{\circ} \mathrm{C}$ in a plastic tube until it was assayed. Brains and entire internal organs in the body cavity were collected and fixed with $4 \%$ paraformaldehyde (PFA) in $0.1 \mathrm{M}$ phosphate buffer (PB). Brains were stored in PFA at $4{ }^{\circ} \mathrm{C}$ for 7 to 10 days until use. After the internal organs had been completely fixed, the gonads were removed under a stereomicroscope and weighed to determine the gonadosomatic index (GSI). GSI was calculated as gonad mass $(\mathrm{g}) /$ body mass $(\mathrm{g}) \times 100$. Gonads were then soaked again in PFA and stored at $4{ }^{\circ} \mathrm{C}$ until use.

\section{Hormone Assays}

Plasma was diluted 100 times by enzyme immunoassay (EIA) buffer, and the concentrations of testosterone, 11ketotestosterone (11-KT), estradiol $\left(\mathrm{E}_{2}\right)$, and cortisol were measured by using commercially available EIA kits (Cayman Chemical, Ann Arbor, MI). All concentrations were measured in duplicate. Inter- and intra-assay coefficients of variation were $16.3 \%$ and $5.0 \%$ for testosterone, $8.2 \%$ and $8.3 \%$ for $11-\mathrm{KT}, 14.7 \%$ and $7.3 \%$ for $\mathrm{E} 2$, and $7.6 \%$ and $8.4 \%$ for cortisol, respectively.

\section{Gonadal Histology}

Gonads were dehydrated and embedded in paraffin. Tenmicrometer sections of gonadal tissue were cut on a standard microtome and stained with haematoxylin and eosin.

\section{Brain Immunohistochemistry}

Brains were saturated with $30 \%$ sucrose in $\mathrm{PB}$ at $4{ }^{\circ} \mathrm{C}$ for $18 \mathrm{~h}$ and then embedded in Agarose Type IX (SigmaAldrich) at $-20{ }^{\circ} \mathrm{C}$. Ten-micrometer transverse sections of whole brain were cut on a cryostat, thaw mounted on MAScoated slides and dried, then stored at $-20^{\circ} \mathrm{C}$ before further processing. The contiguous sections were processed for alternately detecting AVT-ir or IT-ir tissues. Twentymicrometer sagittal sections of whole brain of immature $A$. ocellaris were also made and processed for immunohistochemistry to evaluate the projection patterns of AVT- and IT-ir neurons.

Sections were washed by soaking in $0.1 \mathrm{M}$ PB with Triton $\mathrm{X}-100$ (PBT) for $10 \mathrm{~min}$ and then in $3 \% \mathrm{H}_{2} \mathrm{O}_{2}$ in methanol to eliminate endogenous peroxide activity. Thereafter, the sections were incubated at room temperature with blocking serum (Vectastain ABC kit; Vector Laboratories, Burlingame, CA) in PBT for $60 \mathrm{~min}$ and then incubated for $30 \mathrm{~min}$ at room temperature with a rabbit polyclonal antibody to AVP (Peninsula Laboratories, San Carlos, CA; diluted 1:800) or for $24 \mathrm{~h}$ at $4{ }^{\circ} \mathrm{C}$ with a rabbit polyclonal antibody to OT (RO-2K, Dr. N. Yamamoto, Nagoya University, Nagoya, Japan; diluted $1: 10000$ ) in PB containing $0.5 \%$ bovine serum albumin. After being washed in PBT, the sections were incubated at room temperature with the biotinylated secondary antibody anti-rabbit IgG (Vectastain ABC kit; Vector Laboratories) for $30 \mathrm{~min}$; this was followed by incubation in an avidin and biotinylated horseradish peroxidase macromolecular complex (Vectastain ABC kit; Vector Laboratories) for $30 \mathrm{~min}$. Thereafter, the sections were rinsed with PBT, then incubated with $0.004 \%$ 3, $3^{\prime}$ diaminobenzi-dine (DAB) solution with nickel intensification for about 2.5 min and observed under a light microscope. Digitized images of sections with immunoreactive neurons were captured at $40 \times$ magnification, and the number and size of immnoreactive neurons in the POA were determined by using the public-domain software Image J 1.32 j (Wayne Rasband, NIH, Bethesda, MD). Cell number was counted by visual inspection of the captured images, and cell size was measured by tracing the outside margin of the soma. Our 
preliminary study revealed that there was no significant difference between the right and left hemispheres of the brain with regard to immunoreactive neuron number and size. Therefore, we measured all parvocellular, magnocellular, and gigantocellular neurons in the POA from the left hemisphere of the brain of each fish.

Preadsorption tests on anti-AVT and anti-IT sera were omitted because their specificity had already been verified $[5,7-10]$.

\section{Statistics}

Statistical analyses were performed with StatView + Graphics 5.0J software (Abacus Concepts, Inc., Berkeley, CA; no longer available). A probability of $P<0.05$ was considered to indicate statistical significance. To compare behavioral elements, we used a repeated two-way multivariate analysis of variance (MANOVA) followed by the Fisher's protected least significant differences (PLSD). The relationship between body mass and immunoreactive neuron number and size was investigated by Pearson's correlation coefficient analysis. Physical parameters, plasma steroid concentrations, and immunoreactive neuron number and size were compared by using the paired $t$-test.

\section{RESULTS}

\section{Physical Parameters}

Alpha individuals had a larger body mass, but GSI did not indicate a sex differentiation. Body length $(t[3]=3.781$, $P=0.03)$ and body weight $(t[3]=9.707, P=0.01)$ were significantly longer and heavier, respectively, in $\alpha$ individuals than $\beta$ individuals. GSI did not differ significantly between the experimental groups $(t[3]=-0.216, P=0.84)$ (Table 2).

Table 2. Body Mass and Length of $A$. ocellaris $(n=4)$. Values are means \pm SE $(*, \mathrm{P}<0.05$, paired $t$-test $)$

\begin{tabular}{|c|c|c|}
\hline & $\boldsymbol{\alpha}$ & $\boldsymbol{\beta}$ \\
\hline \hline Body length (mm) & $54.75 \pm 1.38$ & $50.25 \pm 1.60^{*}$ \\
\hline Body mass (g) & $3.61 \pm 0.20$ & $2.70 \pm 0.26^{*}$ \\
\hline GSI & $0.13 \pm 0.05$ & $0.20 \pm 0.06$ \\
\hline
\end{tabular}

\section{Resident-Intruder Model Test}

The agonistic behavior of $\alpha$ individuals gradually increased over time, although displacement aggression, i.e. aggressiveness toward tank mates, was more intense than toward intruders. MANOVA revealed a significant interaction effect between time and social rank on the frequency of displacement $\left(F_{2,5}=16.40, P=0.05\right)$, and post hoc analysis revealed that $\alpha$ individuals lunged at their tank mates more frequently than $\beta$ individuals on Days 259, 343, and 427 of the experiment. Although the frequency of lunging tended to increase in later stages of the experiment in $\alpha$ individuals, there was no significant time course $\times$ social rank interaction effect $\left(F_{2,5}=4.16, P=0.21\right)$ or other parameters $\left(F_{2,5}=0.26\right.$, $P=0.45$ for approach; $F_{2,5}=3.61, P=0.23$ for latency; and $F_{2,5}=1.54, P=0.44$ for touch) (Fig. 1).
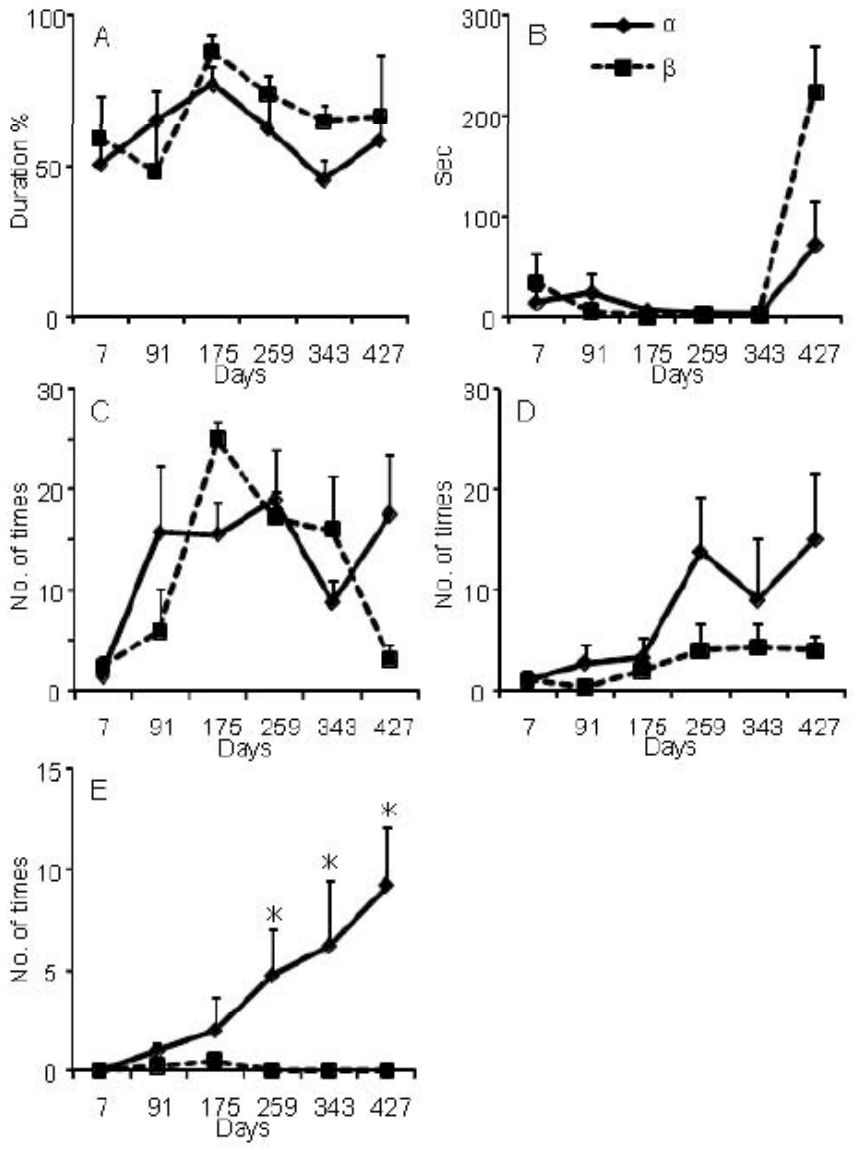

Fig. (1). Changes in behaviors over time, as assessed by the resident-intruder model test in $\alpha$ and $\beta$ individuals kept together for 450 days $(\mathrm{n}=4)$; (A) approach, (B) latency, (C) touch, (D) lunging, and $(\mathbf{E})$ displacement. Data points represent means $\pm \mathrm{SE}(*$, $P<0.05$ MANOVA, $P<0.05$, Fisher's PLSD).

\section{Steroid Hormone Profiles}

The blood steroids levels did not indicate a sex differentiation between social ranks. There was no significant difference in plasma concentrations of $11-\mathrm{KT}(t[3]=0.64, P=$ $0.56)$, testosterone $(t[3]=-0.79, P=0.17)$, estradiol $(t[3]=-$ $1.40, P=0.26)$, or cortisol $(t[3]=0.29, P=0.79)$ between $\alpha$ and $\beta$ individuals (Table $\mathbf{3}$ ).

Table 3. Sex-Steroid Profiles of A. ocellaris $(n=4)$. Values are means \pm SE $(*, P<0.05$, paired $t$-test $)$

\begin{tabular}{|l|c|c|}
\hline & $\alpha$ & $\beta$ \\
\hline \hline $11-\mathrm{KT}(\mathrm{ng} / \mathrm{ml})$ & $3.08 \pm 0.42$ & $2.11 \pm 0.41$ \\
\hline Testosterone $(\mathrm{ng} / \mathrm{ml})$ & $0.33 \pm 0.12$ & $0.24 \pm 0.19$ \\
\hline Estradiol $(\mathrm{pg} / \mathrm{ml})$ & $242.71 \pm 10.51$ & $390.90 \pm 11.29$ \\
\hline Cortisol $(\mathrm{ng} / \mathrm{ml})$ & $14.93 \pm 4.97$ & $12.70 \pm 5.14$ \\
\hline
\end{tabular}

\section{Histology}

The histological observation of gonads in $\alpha$ individuals differ little from those in $\beta$ individuals. Hematoxylin and 
eosin staining revealed that all experimental fish had ovotestes with oocytes and spermatogenic germ cells. No signs of sex differentiation, i.e., developmental or regressive change of oocytes, were observed (Fig. 2).

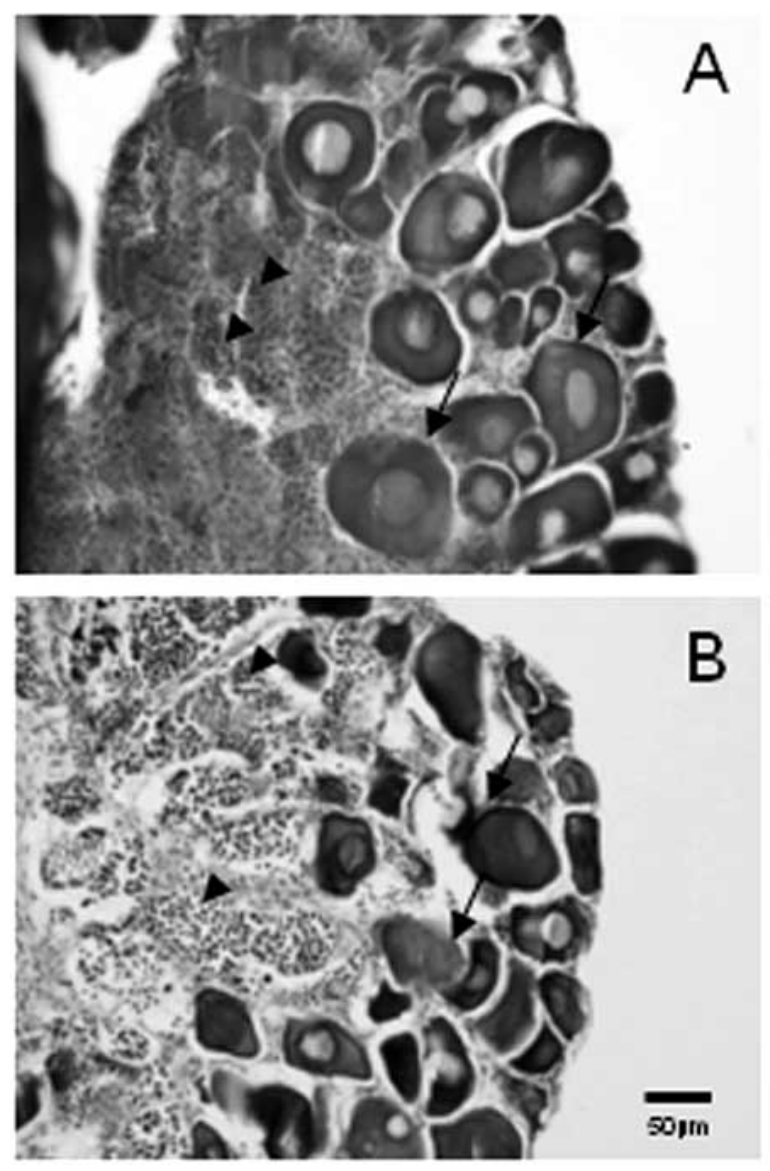

Fig. (2). Light micrographs showing the gonadal structure of Amphiprion ocellaris after 450 days of being paired; sections were stained with hematoxylin and eosin. Oocytes (arrow) and spermatogenic germ cells (arrowhead) were observed in (A) $\alpha$ and (B) $\beta$ individuals. Scale bar $=50 \mu \mathrm{m}$.

\section{AVT and IT Immunocytochemistry}

Although body size and weight of the experimental fish differed significantly between $\alpha$ and $\beta$ individuals (Table 2), there was no significant relationship between body mass and the number and size of AVT- or IT-ir neurons in each layer, with the exception of the number of IT-ir neurons in the parvocellular layer (Pearson's correlation coefficient $r=0.715$, $P=0.045$; Table 4). Therefore, the differences in the number and size of AVT- or IT-ir neurons between $\alpha$ and $\beta$ individuals were compared without mass corrections.

IT immunoreactivity in transverse sections occurred in similar locations as AVT immunoreactivity in the parvocellular, magnocellular, and gigantocellular layers of the POA but was found in different cell bodies (Fig. 3). Paired $t$-test revealed that $\alpha$ individuals had a greater number of IT-ir neurons in the parvocellular layer $(t[3]=7.89, P<0.001)$ and larger AVT-ir neurons in the magnocellular layer $(t[3]=$ $4.18, P=0.02)$ than $\beta$ individuals. There were no significant differences in other parameters (Fig. 4).

AVT- and IT-ir neurons in sagittal sections showed parallel projection patterns. In the magnocellular layer, immunoreactive fibers extended rostrally to the medial zone of the telencephalon (DM), caudally to the mesencephalic tegmentum, and dorsally to the thalamus as well as to the pituitary (Fig. 5B and E). In contrast, immunoreactive cell bodies in the parvocellular and gigantocellular layers extended long, beaded fibers to innervate the pituitary. Some of these fibers extended laterally and dorsally, but many contributed to the pituitary-hypophyseal tract (Fig. $\mathbf{5 A}, \mathbf{C}, \mathbf{D}$ and $\mathbf{F}$ ). The projection of AVT-ir fibers innervating the telencephalon spread throughout the medial zone of the dorsal telencephalon, whereas the projection of IT-ir fibers was limited to the central zone of the DM. The density of IT-ir fibers was greater than that of AVT-ir fibers in the thalamus.

\section{DISCUSSION AND CONCLUSION}

Neurochemical responses to social interaction in animal groups generally result in behavioral change in individuals. In both male and female mammals, the brain nanopeptides arginine vasopressin (AVP) and oxytocin (OT) are implicated in social behavior. AVP, known for its peripheral actions as an antidiuretic hormone, is synthesized in the central nervous system under the influence of testosterone and shows a sexually dimorphic system. AVP regulates typical male social behaviors, i.e., scent marking [11], aggression [12], and paternal care [13]. The roles of OT in the peripheral circulation include the induction of parturition and ejection of milk during lactation, whereas central OT is associ-

Table 4. Correlation Coefficients Between Body Mass and AVT-ir Cell Number and Size in each Pre-optic Area Layer of $A$. ocellaris $(\mathrm{n}=4)$. $(*, P<0.05$, Pearson's Correlation Coefficient)

\begin{tabular}{|c|c|c|c|c|c|c|c|c|}
\hline & \multicolumn{4}{|c|}{ Number of Neurons } & \multicolumn{4}{|c|}{ Size of Neurons } \\
\hline & \multicolumn{2}{|c|}{ AVT } & \multicolumn{2}{|c|}{ IST } & \multicolumn{2}{|c|}{ AVT } & \multicolumn{2}{|c|}{ IST } \\
\hline & $r$ & $P$ value & $r$ & $P$ value & $r$ & $P$ value & $r$ & $P$ value \\
\hline Parvocellular & 0.349 & 0.412 & $0.715^{*}$ & 0.045 & 0.457 & 0.269 & 0.249 & 0.569 \\
\hline Magnocellular & -0.586 & 0.133 & -0.504 & 0.215 & 0.66 & 0.076 & 0.647 & 0.085 \\
\hline Giantcellular & -0.067 & 0.881 & 0.528 & 0.1895 & 0.633 & 0.095 & 0.629 & 0.096 \\
\hline
\end{tabular}



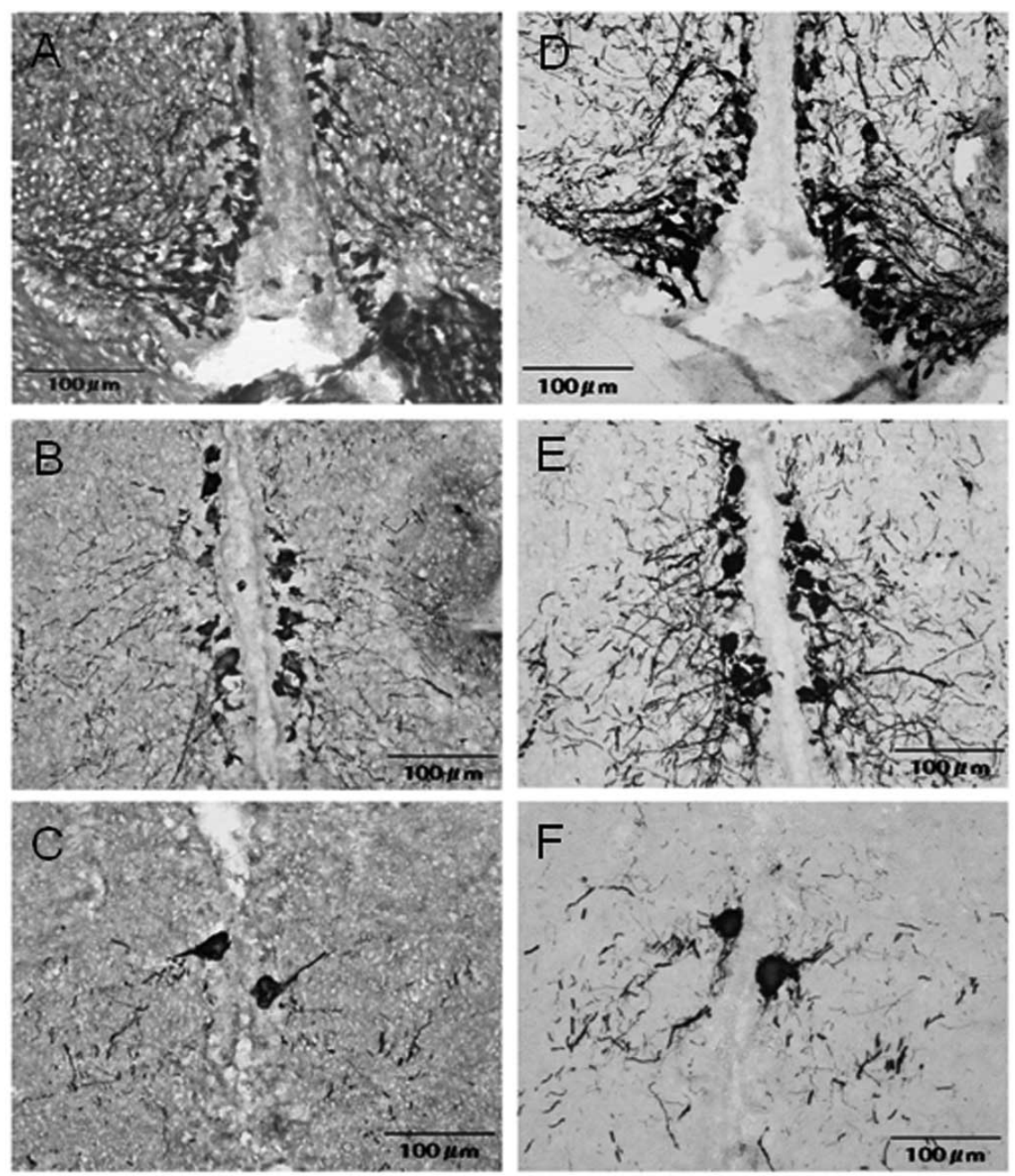

Fig. (3). Representative images of immunoreactive (ir) staining in transverse sections of the preoptic area (POA) of A. ocellaris at 450 days: (A) parvocellular AVT-ir, (B) magnocellular AVT-ir, (C) gigantocellular AVT-ir, (D) parvocellular IT-ir, (E) magnocellular IT-ir, and (F) gigantocellular IT-ir neurons. Scale bar $=100 \mu \mathrm{m}$.

ated with male parental care as well as the onset of maternal behavior [14]. Both AVP and OT are important for social recognition in rats and mice [15], and one study has shown that these peptides are involved in pair-bond formation in monogamous prairie voles [16].

Arginine vasotocin (AVT) and isotocin (IT) are the ancestral peptides of AVP and OT and are thought to be engaged in social and reproductive behavior in teleosts. Brain AVT is involved in aggression [17], courtship [18], and the highly plastic mechanism of sex determination in the brains of some species of sex-changing fish [19]. By contrast, there is evidence that IT can modulate social approach [20], male vocalization [21], and sex change [22], but little is known about the functional role of IT in teleost species.

In the present study, $\alpha$ individuals on average had a larger body mass and showed greater aggressiveness than $\beta$ individuals, but there were no indication of sex differentiation between the social ranks after 450 days of pairing. However, immunohistochemical examination showed that $\alpha$ individuals had a greater number of IT-ir neurons in the parvocellular layer and a larger AVT-ir neurons in the magnocellular layer compared with $\beta$ individuals. An observable relationship between body mass and the number and size of AVT and IT-ir neurons was not evident. Our previous study [5] indicated that the number and size of AVT-ir neurons in the POA were notably influenced by body mass after 90 days of pairing, and the results with mass-corrected data showed that the number of AVT-ir neurons in the magnocellular layer declined with increasing hierarchical dominance. This contradicts our present results, which show the same trend with or without mass correction (data not shown). Variations in brain AVT phenotype have been linked to variations in reproductive roles [23-25]. Thus, it is possible that the role of these nanopeptides changes over time, for example, during social group formation, social hierarchy maintenance, and sex differentiation.

Modulation of the AVT phenotype by social rank was apparent only in the magnocellular layer in the POA. The magnocellular layer of the POA in teleosts may be homologous to the paraventricular nucleus of the hypothalamus in mammals, which integrates aggressive and reproductive behavior [26]. The fibers of these neurons also project densely to the thalamus. Furthermore, the medial zone of the telencephalon, which is innervated by neurons from the magnocellular layer of the POA, may be homologous to the mam- 

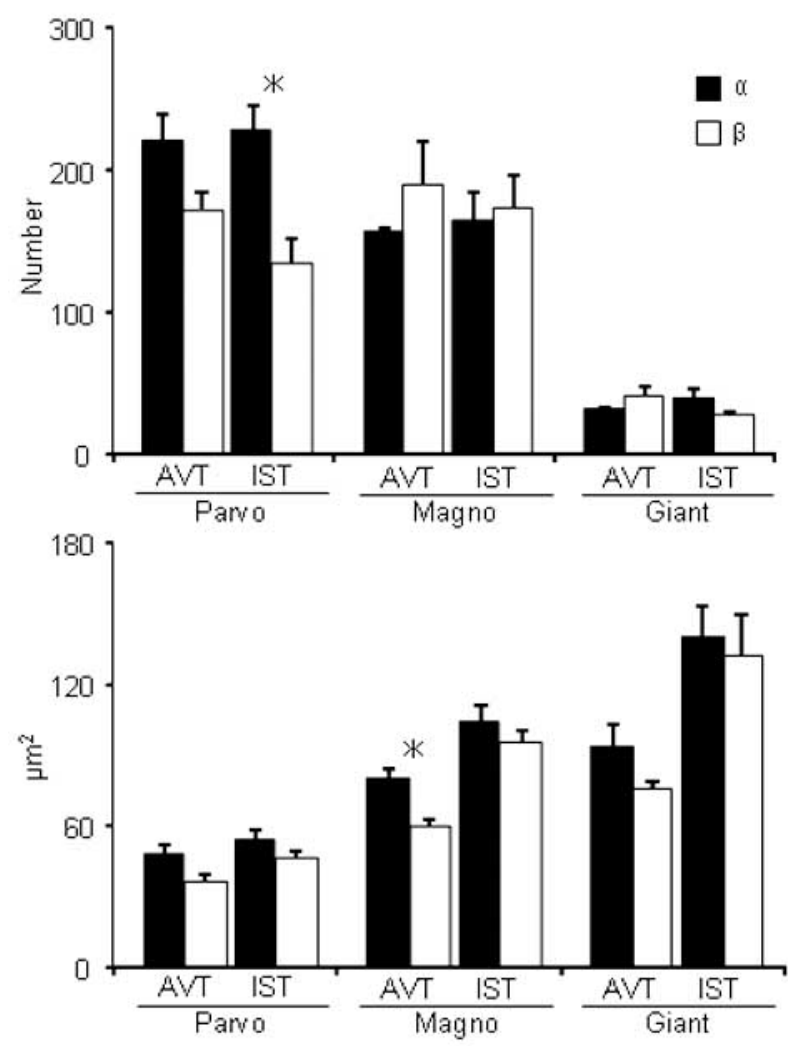

Fig. (4). Numbers and sizes of AVT and IT-ir neurons of A. ocellaris at 450 days $(\mathrm{n}=4)$. Upper, number of neurons; Lower, neuron size. Mean $\pm \mathrm{SE}(*, P<0.05$, Paired $t$-test $)$.

malian striatum or amygdala [27]. These results suggest that AVT plays an important role in the regulation of emotional behavior. Additionally, IT neurons in the magnocellular layer had the same projection pattern as AVT neurons, and the IT-ir fibers seemed to more densely innervate the thalamus than the telencephalon. These results suggest that IT neurons in the magnocellular layer also play a role for the regulation of behavior.

Amphiprion ocellaris $\alpha$ individuals had a greater number of IT neurons in the parvocellular layer of the POA than did $\beta$ individuals. The axons of the IT neurons in the parvocellular layer seemed to project only to the pituitary, but it is still possible that IT modulates some specific behaviors. In pupfish, Cyprinodon nevadensis (Miller, 1948), AVT alters aggression levels of individuals and brain AVT-ir neurons project only to the pituitary [17]. IT is also reported to regulate female-specific behavior. IT-ir neuron numbers tend to decrease during female-to-male sex change in Lythrypnus dalli (Gilbert, 1890) [22], whereas AVT-ir neuron size increases [28]. In contrast, there is evidence that AVT and IT work in a coordinated manner. In the sonic midshipman fish Porichthys notatus (Girard, 1854), both mesotocin /OT-ir and AVPir fibers densely innervate sites of vocal-acoustic integration [21]. The roles of IT remain unclear in the present study; however, it is still possible that IT plays an important role in the behavioral regulation of $\alpha$ individuals, which may become females in the future.
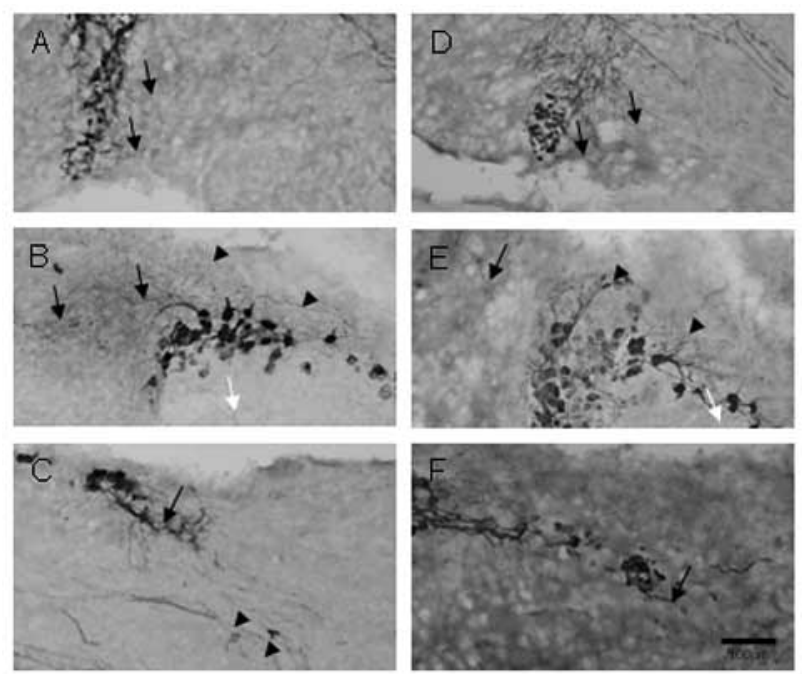

Fig. (5). Representative images of AVT-ir staining in sagittal sections of the POA. AVT-ir (A) and IT-ir (D) neurons in the parvocellular layer with fibers extending to the pituitary (arrow). AVT-ir (B) and IT-ir (E) cell body and fiber staining of magnocellular neurons, showing fibers extending rostrally to the telencephalon (arrow) and caudally to the mesencephalic tegmentum (arrowhead). Fibers projecting to the pituitary are also seen (white arrow). AVTir (C) and IT-ir (F) cells in the gigantocellular layer, with fibers projecting to the pituitary (arrow). Fibers from parvocellular layer neurons projecting to the pituitary are also shown (arrowhead).

In the resident-intruder model tests, agonistic behavior of $\alpha$ individuals gradually increased over time, although displacement aggression, i.e. aggressiveness toward tank mates, was more intense than toward intruders. Displacement aggression has previously been reported in teleosts as well as mammals and is thought to be a behavioral stress-coping strategy [29]. It was reported that the expression of displaced behavior of nonterritorial males of African cichlid fish Astatotilapia burtoni (Günther, 1893) might due to the unstable social condition [30]. In the present study, the intensive displacement behavior in $\alpha$ individuals may be a result of the halfway development of territoriality due to sexual immaturity.

We demonstrated that social rank formation and social hierarchy maintenance in immature A. ocellaris modulate AVT and IT-ir neurons in the POA and sex differentiation was not indispensable. Our results also suggest that the roles of brain AVT and IT change over time. Although the phenotypes of AVT and IT neurons of A. ocellaris appeared to differ, the essential roles of both peptides remain unclear. Further investigations, such as studies of the entire process of sex differentiation or neuropharmacological studies, are needed.

\section{ACKNOWLEDGEMENTS}

We thank Dr. Takeshi Huruta at Central Research Institute of Electric Power Industry for providing the amenomefish used in this study. We also thank Dr. Naoyuki Yamamoto at Nagoya University for providing a rabbit polyclonal antibody to OT. 


\section{REFERENCES}

[1] Fricke H, Fricke S. Monogamy and sex change by aggressive dominance in coral reef fish. Nature 1977; 266: 830-2.

[2] Moyer JT, Nakazono A. Protandrous hermaphroditism in six species of the anemonefish genus Amphiprion in Japan. Jpn J Ichthyol 1978; 25: 101-106.

[3] Ochi H. Acquisition of breeding space by nonbreeders in the anemonefish Amphiprion clarkii in temperate waters of southern Japan. Ethology 1989; 83: 279-94.

[4] Goldstein R. Breeding marine clownfish. Aquar Fish Magn 1989; 1: 32 .

[5] Iwata E, Nagai Y, Sasaki H. Social rank modulates brain arginine vasotocin immunoreactivity in false clown anemonefish ( $\mathrm{Am}$ phiprion ocellaris) Fish Physiol Biochem 2009 [Epub ahead of print].

[6] Iwata E, Nagai Y, Hyoudou M, Sasaki H. Social environment and sex differentiation in false clown anemonefish, Amphiprion ocellaris. Zool Sci 2008; 25: 123-8.

[7] Kawamoto K. Immunohistochemical study of vasopressin and oxytocin in the neurosecretory system during reorganization of the neural lobe in mice. Zool Sci 1985; 2: 371-80.

[8] Haruta K, Yamashita T, Kawashima S. Changes in arginine vasotocin content in the pituitary of the Medaka (Oryzias latipes) during osmotic stress. Gen Comp Endocrinol 1991; 83: 327-36.

[9] Yamamoto N, Oka Y, Amano, Aida K, Hasegawa Y, Kawashima S. Multiple gonadotropin-releasing hormone (GnRH)immunoreactive systems in the brain of the dwarf gourami, Colisa lalia: immunohistochemistry and radioimmunoassay. J Comp Neurol 1995; 355: 354-68.

[10] Bordieri L, Cioni C. Co-localization of neuronal nitric oxide synthase with arginine-vasotocin in the preoptic-hypothalamohypophyseal system of the teleost Oreochromis niloticus. Brain Res 2004; 1015: 181-5.

[11] Delville Y, De Vries GJ, Schwartz WJ, Ferris CF. Flank-marking behavior and the neural distribution of vasopressin innervation in golden hamsters with suprachiasmatic lesions. Behav Neurosci 1998; 112: 1486-501.

[12] Ferris CF, Melloni RH, Jr., Koppel G Perry, KW, Fuller RW, Deville Y. Vasopressin/serotonin interactions in the anterior hypothalamus control aggressive behavior in golden hamsters. J Neurosci 1997; 17: 4331-40.

[13] Wang Z, Ferris CF, De Vries GJ. Role of septal vasopressin innervation in paternal behavior in prairie voles (Microtus ochrogaster). Proc Natl Acad Sci USA 1994; 91: 400-4.

[14] Campbell A. Attachment, aggression and affiliation: The role of oxytocin in female social behavior. Biol Psychol 2008; 77: 1-10.
[15] Choleris E, Clipperton-Allen AE, Phan A, Kavaliers M. Neuroendocrinology of social information processing in rats and mice. Front Neuroendocrinol 2009; 30: 442-59.

[16] Young LJ, Wang Z. The neurobiology of pair bonding. Nat Neurosci 2004; 7: 1048-54.

[17] Lema SC, Nevitt GA. Exogenous vasotocin alters aggression during agonistic exchanges in male Amargosa River pupfish (Cyprinodon nevadensis amargosae). Horm Behav 2004; 46: 628-37.

[18] Salek SJ, Sullivan CV, Godwin J. Arginine vasotocin effects on courtship behavior in male white perch (Morone americana). Behav Brain Res 2002; 133: 177-83.

[19] Semsar K, Kandel FL, Godwin J. Manipulations of the AVT system shift social status and related courtship and aggressive behavior in the bluehead wrasse. Horm Behav 2001; 40: 21-31.

[20] Thompson RR, Walton JC. Peptide effects on social behavior: effects of vasotocin and isotocin on social approach behavior in male goldfish (Carassius auratus). Behav Neurosci 2004; 118: 620-6.

[21] Goodson JL, Evans AK, Bass AH. Putative isotocin distributions in sonic fish: relation to vasotocin and vocal-acoustic circuitry. J Comp Neurol 2003; 462: 1-14.

[22] Black MP, Reavis RH, Grober MS. Socially induced sex change regulates forebrain isotocin in Lythrypnus dalli. Neuroreport 2004; 15: $185-9$.

[23] Grober MS. Socially controlled sex change: Integrating ultimate and proximate levels of analysis. Acta Ethol 1998; 1: 3-17.

[24] Grober MS, George AA, Watkins KK, Carmeiro LA, Oliveria RF. Forebrain AVT and courtship in a fish with male alternative reproductive tactics. Brain Res Bull 2002; 57: 423-5.

[25] Aubin-Horth N, Desjardins JK, Martei YM, Balshine S, Hofmann HA. Masculinized dominant females in a cooperatively breeding species. Mol Ecol 2007; 16: 1349-58.

[26] Semsar K, Perreault HA, Godwin J. Fluoxetine-treated male wrasses exhibit low AVT expression. Brain Res 2004; 1029: 141-7.

[27] Northcutt RG, Davis RE. Telencephalon organization in ray-finned fishes. In: Fish Neurobiology. Northcutt RG, Davis RE, Eds. University of Michigan Press 1983; pp. 203-36.

[28] Reavis RH, Grober MS. An alternative approach to sex change: social, behavioral and neurochemical cahges in Lythrypnus dalli (Pisces). Acta Ethol 1999; 2: 51-60.

[29] Overli O, Korzan WJ, Larson ET, Winberg S, et al. Behavioral and neuroendocrine correlates of displaced aggression in trout. Horm Behav 2004; 45: 324-9.

[30] Clement TS, Parikh V, Schrumpf M, Fernald RD. Behavioral coping strategies in a cichlid fish: the role of social status and acute stress response in direct and displaced aggression. Horm Behav 2005; 47: 336-42.

$\begin{array}{lll}\text { Received: December 08, } 2009 & \text { Revised: April 05, 2010 } & \text { Accepted: April 14, 2010 }\end{array}$

(C) Iwata et al.; Licensee Bentham Open.

This is an open access article licensed under the terms of the Creative Commons Attribution Non-Commercial License (http://creativecommons.org/licenses/by-nc/3.0/) which permits unrestricted, non-commercial use, distribution and reproduction in any medium, provided the work is properly cited. 